\title{
Research Paper: Attitudes of Patients and Their Families Towards Medical Privacy and Competence of Bearer or Receiver of Bad News
}

\author{
Maryam Zaare Nahandi' 1 , Mohammad Asghari Jafarabadi ${ }^{2}$, Mehrnoosh Haghighatjou ${ }^{3}$, Kosar Ashrafrezaei ${ }^{4}$, Marziyeh Shakeri Saeed- \\ abad $^{5}$, Ahad Banagozar Mohammadi ${ }^{6}$, Ali Banagozar Mohammadi ${ }^{7 *}$ (i) \\ 1. Kidney Research Center, Tabriz University of Medical Sciences, Tabriz, Iran. \\ 2. Road Traffic Injury Research Center, Tabriz University of Medical Sciences, Tabriz, Iran. \\ 3. Medical Toxicology Research Center, Mashhad University of Medical Sciences, Mashhad, Iran \\ 4. Department of Pathology, School of Medicine, Urmia University of Medical Sciences, Urmia, Iran. \\ 5. Sina Educational Research and Treatment Center, Department of Pathology, School of Medicine, Tabriz University of Medical Sciences, Tabriz, Iran. \\ 6. Department of Iranian Traditional Medicine, School of Traditional Medicine, Tabriz University of Medical Sciences, Tabriz, Iran. \\ 7. Sina Educational Research and Treatment Center, Department of Internal Medicine, School of Medicine, Tabriz University of Medical Sciences, Tabriz, Iran.
}

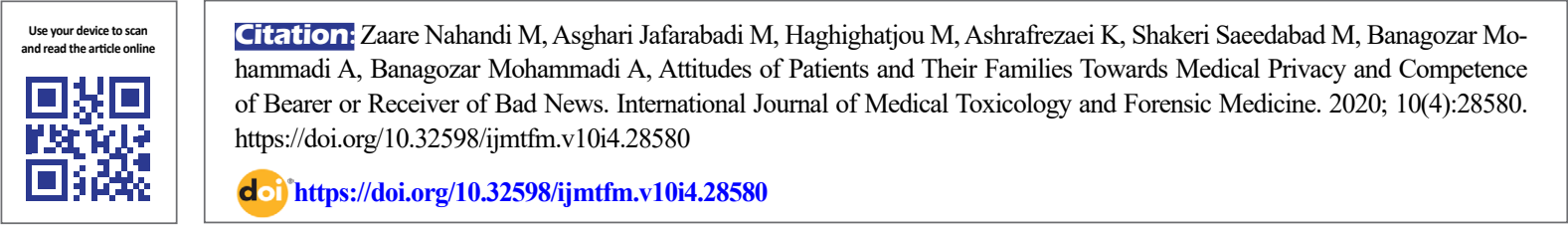

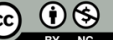

Article info:

Received: 9 Jan 2020

First Revision: 20 Jan 2020

Accepted: 18 May 2020

Published: 12 Dec 2020

\begin{abstract}
Background: Based on the patients' and relatives' views on the level of preservation of privacy rights of individuals, we propose a way to reduce problems and disagreements about the competence of the provider and recipient of bad news.

Methods: In the current cross-sectional study, the participants were recruited from the main northwest hospital of Iran. It was also conducted to study the scope of medical privacy and competence of bearers or receivers of bad news. After the literature review, two questionnaires were designed and administered. They contained items pertinent to the scope of medical privacy and competence of bearers and receivers of bad news. Each item of the original questionnaire was scored on a 5-point Likert scale.

Results: The model quality and significance level were obtained using KMO and Bartlett tests. The results (patient's attitudes questionnaire: $\mathrm{KMO}=0729$ and $\mathrm{P}<0.05$ in the Bartlett test; family attitudes questionnaire: $\mathrm{KMO}=0.764$ and $\mathrm{P}<0.05$ in the Bartlett test) confirmed the model efficiency. According to the results from factor variance and their cumulative rate, the predictive power of the model was obtained as $62.019 \%$, based on the overall factor variance rate. The majority of patients wanted to be informed about their disease conditions. They also considered bad news to be medical privacy and disagreed that their medical information should be opened up with others without permission.
\end{abstract}

Conclusion: To preserve medical privacy, it is recommended that a system be designed that allows patients at the admission to the medical center to enlist their eligible family members to whom medical information can be delivered.
Bad news, Privacy, Patient, Family

\footnotetext{
* Corresponding Author:

Ali Banagozar Mohammadi, MD.

Address: Kidney Research Center, Tabriz University of Medical Sciences, Tabriz, Iran.

Tel: +98 (413) 5498260

E-mail: alibanagozar@gmail.com; alibanagozar@tbzmed.ac.ir
} 


\section{Introduction}

H uman beings have always considered themselves bound to follow a set of principles and rules, known as good or ethical relationships. In building up this relationship, it is very important to develop mutual trust in different ways, such as privacy protection, which is an inescapable pillar in the history of the physician-patient relationship. An inaccurate perception of this principle not only can damage the sanctity of the medical profession, but also may affect the quality of therapeutic relationship in particular, and public health in general [1]. According to the medical laws in Iran, physicians and other medical staff should maintain the security and confidentiality of patient's records, even if it is not emphasized by the patient unless they are excepted by certain laws or judicial authorities 1 . However, some physicians tend to inform the patient's family about his or her conditions, rather than the patient, in particular when it comes to breaking bad news. This may be due to their concerns about the negative impacts of patient disappointment or lack of patient cooperation. A similar tendency exists among the patient's family towards withholding medical information $[1,2]$.

Bad news should be treated as medical privacy; therefore, it is the patient's right to decide whether he or she wants to know or not to know about medical conditions. Some patients might prefer not to receive the bad news, or prefer that the family (not themselves) receive the news. Nevertheless, physicians in many communities are reluctant to break bad news directly to the patients, which is a breach of medical privacy [1, 2]. In Iran, physicians prefer to deliver medical information to family members, instead of the patients3. However, today's general consent requires the protection of all patient's rights to enable them to make logical and informed decisions about their present conditions [1-4]. As a result, they are several protocols for breaking bad news such as ABCDE, BREAKS, PACIENTE, and SPIKES protocol5-9. In some articles SPIKES protocol has been recommended as a preferred guideline for delivering bad news but based on the cultures, these protocols can be different [5-10].

\section{Gaps in the research}

This study intended to address the important challenges facing physician-patient relationship from two different perspectives: medical privacy and bad news from the standpoint of the patients and their families.
Medical privacy refers to the practice of maintaining the security and confidentiality of the patient's records by the physician to preserve trust in medical relationships $[11,12]$. However, the dominant culture and perception of life continue to remain a challenge facing the delivery of medical information in critical cases, such as the disease exacerbation or serious or incurable illnesses $[13,14]$. Physicians should be accountable for delivering bad news to patients. Bad news refers to any information that adversely affects an individual's view of his or her future [14]. It is very difficult to deliver bad news to the patients and it may be associated with unpleasant reactions by them [11-14]. On the other hand, withholding the treatment process from the patients may create a sense of mistrust towards the medical team and harm their psychological and physical conditions [14-18]. Patients usually expect physicians to be honest with them and inform them about the curable or incurable nature of the disease, its treatment complexity, and associated medicinal side effects or surgical complications in compliance with their demands, beliefs, and culture [19-21].

Hancock observed that although the majority of physicians contend that the patients should be completely informed about their conditions, they are practically reluctant to deliver bad news [22].

\section{Differences in societies and cultures}

Although medical ethics reserve patients' rights, in oriental family-centered communities, the family is accountable for deciding for the patient $[13,14]$. This difference between the western and oriental societies has also been reflected in the literature, but it seems that these differences can be overlapped. In western societies, it is important to be open about telling the truth to the patient; whereas, due to the family-centered nature of the oriental societies, families most often withhold medical information from the patients and are reluctant to break the bad news to them [15, 16, 21, 23-29].

\section{Aim}

Considering the limited studies in Iran about the level of preservation of medical and privacy rights of individuals as well as the competence of the provider and recipient of bad news and the religious, cultural, and ethnic differences among various societies and cultures, we cannot use the studies of other countries. Therefore, we have tried to quantitatively evaluate the patients' and relatives views on these issues and, if possible, propose a way to reduce problems and disagreements in this issue. 


\section{Materials and Methods}

\section{Time and Place}

In the current cross-sectional study, the participants $(n=300)$ were recruited only from the 7 wards of the Internal Medicine Department of Imam Reza Hospital of Tabriz, Iran from June 21 to September 21, 2016 (1612 patients were hospitalized in 7 wards of the Internal Medicine Department at that time). It was also conducted to study the scope of medical privacy and competence of bearers or receivers of bad news.

Preparation of a questionnaire: Content validity and face validity of the questionnaire

Based on the problems that the authors experienced in the hospitals (for example failure to keep patients' secrets and privacy, illegal and unethical requests from patients' companions, etc.) and literature review, the authors designed the preliminary questionnaires. After the literature review, two questionnaires were designed and administered, containing items pertinent to the scope of medical privacy and competence of bearer and receivers of bad news. To determine the content validity and face validity of the questionnaires, they were given to an expert panel comprising of 10 specialists in the field of forensic and internal medicine.

The content validity and face validity were qualitatively and quantitatively evaluated. The qualitative modifications were made based on the panel's comments. With respect to quantitative assessment, all items were examined in terms of relevancy, simplicity, and clarity. Besides, the rationale behind each item was evaluated through multiple-choice items. In both questionnaires, the content validity index (CVI) and content validity ratio (CVR) for the first three items, and the current item were respectively obtained as 0.996 and 0.992 . Besides, the impact score was calculated to assess face validity. The necessary modifications were made based on the panel's integrative comments and the measures were confirmed.

\section{Preparation of a questionnaire: Construct validity of the questionnaire}

The exploratory factor analysis was used to assess construct validity. Based on the nature of extracted outputs, the principal component analysis and direct oblimin rotation were used. In this analysis, two aspects of the construct validity (convergent and discriminant validity) were examined. The cutoff point of 0.3 was considered for the factor-item relationship. The model efficiency was evaluated using the KMO index and the Bartlett test.

Each item of the original questionnaire was scored based on a 5-point Likert scale. The scores of each domain, as well as the overall score, were calculated by adding the scores of relevant items. The score range in the patient and family questionnaires were (24-120) and (25-125), respectively.

\section{Preparation of a questionnaire: Internal consis- tency and stability reliability}

The internal consistency and stability reliability of the questionnaire were also assessed. To obtain the internal consistency, a pilot sample comprising of 30 individuals was examined. The results from the Cronbach alpha for the family and patient questionnaires were obtained as 0.7 and 0.62 , respectively. The test-retest with a repetition after 15 days was administered to 30 individuals and the Internal Consistency Calculation (ICC) of 0.74 $(0.45-0.88)$ was obtained.

\section{Data collection}

During the 3-month research period, the researchers attended the Internal Department of Imam Reza Hospital of Tabriz to select among mature and conscious inpatients, as well as their mature family companions. Then, the questionnaires were administered to them after obtaining their informed consent. After attending the Department, the research topic and objectives were explained to the patients and their family companions. Then, the questionnaires were administered among those who tend to participate, and the completed ones were collected.

All patients who were admitted to internal wards during the 3 months, after applying inclusion and exclusion criteria were included in the study.

\section{The inclusion and exclusion criteria}

Eligible participants were mature and conscious patients hospitalized in the internal department, as well as their mature family companions, who completed the consent form.

With respect to the low-literate or illiterate participants (32 patients and 8 family companions), the questionnaire items were read for them and their responses were inserted in the questionnaires. We selected the participants that at least one of them in each group (either patient or family companions) was a literate person and 
had educational level. In this study, 150 eligible patients and 150 eligible family companions were included.

\section{Statistical analysis:}

Statistical analysis was done with SPSS v. 17. The obtained data were presented as Mean \pm SD for the numeric variables and as frequency (percentage) for categorical variables.

\section{Results}

\section{Overall results}

Despite an almost equal number of male and female patients in the internal department, men were more reluctant to participate, so $64 \%$ of patients who signed informed consent were female. Concerning the family companions, $64.7 \%$ were female and $35.3 \%$ male.

The youngest and oldest patients were 19 and 80 years old, respectively. The Mean $\pm \mathrm{SD}$ age of the patients was 43.07 \pm 15.48 , (Median=43) years.

According to the findings, 110 patients (73.3\%) were almost fully aware of their illness and 40 patients (26.7\%) were not aware or did not have accurate information.

In terms of severity, their illness was divided into five groups: acute, chronic, benign, malignant, uncertain (under examination). According to this categorization, there were 65 chronic patients (43.3\%), 60 acute patients $(40 \%), 14$ malignancy-susceptible $(9.3 \%), 6$ patients with benign tumors (4\%), and 5 patients under examination.

The youngest and oldest participants among family companions were 16 and 61 years old, respectively. The mean age of them was $36.75 \pm 12.035$ (Median=35) years old.

The participants' level of education ranged from postgraduate study to a primary (elementary) school education (forty participants were illiterate).

Among the patients' group, the most abundance was among uneducated patients (21.3\%) and next in line was related to those with higher education degrees (bachelor's degree) (18.7\%).

In the group of relatives, the most common were related to patients' companions with diplomas (32\%) and afterward were those with a bachelor's degree (17.3\%).

About the relations between participating patients and their companions in this project, 79 people (52.7\%) were their children (son/daughter) and the rest in decreasing order were sister/brother, spouse, daughter in law, parents, nephew, cousin, grandson, friends, and sister in law.

\section{Results of heuristic and confirmatory factor analysis}

The model quality and significance level were obtained using KMO and Bartlett tests. Results (patient attitude questionnaire: $\mathrm{KMO}=0729$ and $\mathrm{P}<0.05$ in the Bartlett test; family attitude questionnaire: $\mathrm{KMO}=0.764$ and $\mathrm{P}<0.05$ in the Bartlett test) confirmed the model efficiency.

According to the results from factor variance and their cumulative rate, the predictive power of the model was obtained as $62.019 \%$, based on the overall factor variance rate.

\section{The participants' answers}

Items and frequency of selection on the attitudes of patients and their family components are presented in Table 1.

\section{Discussion}

According to the results, the majority of the patients wanted to be informed about their disease conditions. They also considered bad news to be medical privacy and disagreed that their medical information should be opened up with others without their permission. The majority of patients also wanted certain family members (specified at admission) to be informed about their disease process and conditions at the same time.

Although the majority of companions considered bad news to be medical privacy and entitled the patient's rights to know their medical information, their responses to detailed items indicated no family involvement limitation. To them, the family should even receive bad news before the patients.

Among the significant skills of physicians in establishing a physician-patient relationship is their ability to inform patients about the medical conditions and their severity. Regarding the sensitivity of this relationship, physicians' knowledge of a patient's attitude can contribute to better protection of a patient's rights and his or her medical privacy.

According to previous studies, the best protocol is to evaluate the patient's knowledge first, and then provide him or her with necessary information based on his or her culture and literacy or knowledge level3,7,9,30. In this study, $76.7 \%$ of the patients and $86.6 \%$ of their family companions believed that breaking bad news should be based on the psychological, family, and knowledge of the 
Table 1. Items and frequency of selection on attitudes of patients and their family components

\begin{tabular}{|c|c|c|c|c|c|}
\hline \multirow{2}{*}{ Row } & \multirow{2}{*}{$\begin{array}{c}\text { Items on the Attitudes of Hospitalized Patients } \\
\text { and Their Families }\end{array}$} & \multirow{2}{*}{ Group } & \multicolumn{3}{|c|}{ No. (\%) } \\
\hline & & & Agree & Neutral & Disagree \\
\hline \multirow{2}{*}{1} & \multirow{2}{*}{$\begin{array}{l}\text { All patients should know the truth about their } \\
\text { medical conditions }\end{array}$} & Patients & $130(86.7)$ & $8(5.3)$ & $12(8)$ \\
\hline & & Family companion & $104(69.4)$ & $9(6)$ & $37(24.6)$ \\
\hline \multirow{2}{*}{2} & \multirow{2}{*}{$\begin{array}{l}\text { Patients should know the truth about their disease } \\
\text { conditions, regardless of their psychological state }\end{array}$} & Patients & $66(44)$ & $26(17.3)$ & $58(36.7)$ \\
\hline & & Family companion & $52(34.7)$ & $14(9.3)$ & $84(56)$ \\
\hline \multirow{2}{*}{3} & \multirow{2}{*}{$\begin{array}{l}\text { Patients should know the truth about their disease } \\
\text { conditions, regardless of their physiological state }\end{array}$} & Patients & $85(56.7)$ & $21(14)$ & $44(29.3)$ \\
\hline & & Family companion & $72(48)$ & $14(9.3)$ & $64(42.7)$ \\
\hline \multirow{2}{*}{4} & \multirow{2}{*}{$\begin{array}{l}\text { Incurable patients should know the truth about } \\
\text { their chance of cure }\end{array}$} & Patients & $77(51.3)$ & $27(18)$ & $46(30.7)$ \\
\hline & & Family companion & $70(46.7)$ & $16(10.7)$ & $64(42.6)$ \\
\hline \multirow{3}{*}{5} & \multirow{3}{*}{ Bad news must be delivered to patients } & Patients & $55(36.7)$ & $25(16.6)$ & $70(46.7)$ \\
\hline & & & & & \\
\hline & & Family companion & $37(24.7)$ & $17(11.3)$ & $96(64)$ \\
\hline \multirow{2}{*}{6} & \multirow{2}{*}{$\begin{array}{l}\text { Bad news must be delivered to the patient's family } \\
\text { companion }\end{array}$} & Patients & $109(72.7)$ & $21(14)$ & $20(13.3)$ \\
\hline & & Family companion & $121(80.7)$ & $14(9.3)$ & $15(10)$ \\
\hline \multirow{3}{*}{7} & \multirow{3}{*}{ Bad news is considered a patient's confidentiality } & Patients & $110(73.3)$ & $25(16.7)$ & $15(10)$ \\
\hline & & & & & \\
\hline & & Family companion & $99(66)$ & $26(17.3)$ & $25(16.7)$ \\
\hline \multirow{2}{*}{8} & \multirow{2}{*}{$\begin{array}{l}\text { Bad news should not be delivered to anyone other } \\
\text { than the patients without their permission }\end{array}$} & Patients & $96(64)$ & $22(14.7)$ & $32(21.3)$ \\
\hline & & Family companion & $62(41.3)$ & $18(12)$ & $70(46.7)$ \\
\hline \multirow{2}{*}{9} & \multirow{2}{*}{$\begin{array}{l}\text { The act of breaking or withholding bad news } \\
\text { should be in favor of patients }\end{array}$} & Patients & 115 (76.7) & $14(9.3)$ & $15(10)$ \\
\hline & & Family companion & $130(86.7)$ & $5(3.3)$ & $15(10)$ \\
\hline \multirow{2}{*}{10} & \multirow{2}{*}{$\begin{array}{l}\text { Breaking bad news to patients is always to their } \\
\text { advantage }\end{array}$} & Patients & $49(32.7)$ & $20(13.3)$ & $81(54)$ \\
\hline & & Family companion & $17(11.3)$ & $21(14)$ & $112(74.7)$ \\
\hline \multirow{2}{*}{11} & \multirow{2}{*}{$\begin{array}{l}\text { At the admission to the medical center, the pa- } \\
\text { tients should provide a list of the people to whom } \\
\text { bad news should be delivered }\end{array}$} & Patients & $124(82.7)$ & $20(13.3)$ & $15(10)$ \\
\hline & & Family companion & $118(78.7)$ & $20(13.3)$ & $12(8)$ \\
\hline \multirow{2}{*}{12} & \multirow{2}{*}{$\begin{array}{l}\text { Before directly delivering bad news to patients, } \\
\text { the information concerning their disease should } \\
\text { be evaluated }\end{array}$} & Patients & $135(90)$ & $5(3.3)$ & $10(6.7)$ \\
\hline & & Family companion & $135(90)$ & $4(2.7)$ & $11(7.3)$ \\
\hline \multirow{2}{*}{13} & Before directly delivering bad news to patients, & Patients & $94(62.7)$ & $34(22.6)$ & $22(14.7)$ \\
\hline & & Family companion & $108(72)$ & $27(18)$ & $15(10)$ \\
\hline 14 & Informing patients about their disease conditions & Patients & $126(84)$ & $9(6)$ & $15(10)$ \\
\hline & should be proportional to their level of knowledge & Family companion & $124(82.7)$ & $16(10.7)$ & $10(6.6)$ \\
\hline 15 & Physicians may not withhold medical information & Patients & 109 (72.7) & $31(20.6)$ & $10(6.7)$ \\
\hline & even if patients do not ask about it & Family companion & $96(64)$ & $10(6.7)$ & $44(29.3)$ \\
\hline
\end{tabular}




\begin{tabular}{|c|c|c|c|c|c|}
\hline \multirow{2}{*}{ Row } & \multirow{2}{*}{$\begin{array}{l}\text { Items on the Attitudes of Hospitalized Patients } \\
\text { and Their Families }\end{array}$} & \multirow{2}{*}{ Group } & \multicolumn{3}{|c|}{ No. (\%) } \\
\hline & & & Agree & Neutral & Disagree \\
\hline \multirow{2}{*}{16} & \multirow{2}{*}{$\begin{array}{l}\text { Physicians may not withhold medical information } \\
\text { even if patients' companions do not ask about it }\end{array}$} & Patients* & - & - & - \\
\hline & & Family companion & $136(90.7)$ & $4(2.7)$ & $10(6.6)$ \\
\hline \multirow{2}{*}{17} & \multirow{2}{*}{$\begin{array}{l}\text { All information demanded by the patients } \\
\text { concerning their medical conditions should be } \\
\text { provided }\end{array}$} & Patients & $138(92)$ & $6(4)$ & $6(4)$ \\
\hline & & Family companion & $109(72.7)$ & $4(2.7)$ & $37(24.6)$ \\
\hline \multirow{2}{*}{18} & \multirow{2}{*}{$\begin{array}{l}\text { All information demanded by the patients' family } \\
\text { companion concerning their medical conditions } \\
\text { should be provided }\end{array}$} & Patients & $98(65.3)$ & $11(7.4)$ & $41(27.3)$ \\
\hline & & Family companion & $123(82)$ & $14(9.3)$ & $13(8.7)$ \\
\hline \multirow{2}{*}{19} & \multirow{2}{*}{$\begin{array}{l}\text { Bad news should be delivered to the patients by } \\
\text { the medical staff }\end{array}$} & Patients & $108(72)$ & $20(13.3)$ & $22(14.7)$ \\
\hline & & Family companion & $81(54)$ & $15(10)$ & $54(36)$ \\
\hline \multirow{2}{*}{20} & \multirow{2}{*}{$\begin{array}{l}\text { Bad news should be delivered to patients by their } \\
\text { family companion }\end{array}$} & Patients & $47(31.3)$ & $29(19.3)$ & 74 (49.4) \\
\hline & & Family companion & $71(47.3)$ & $32(21.3)$ & 47 (31.4) \\
\hline \multirow{2}{*}{21} & \multirow{2}{*}{$\begin{array}{l}\text { Bad news, as well as medical information of } \\
\text { patients, must be delivered first to their family } \\
\text { companion }\end{array}$} & Patients & $87(58)$ & $23(15.3)$ & 40 (26.7) \\
\hline & & Family companion & $133(88.7)$ & $4(2.7)$ & $13(8.6)$ \\
\hline \multirow{2}{*}{22} & \multirow{2}{*}{$\begin{array}{l}\text { Family companions must be informed about pa- } \\
\text { tients' conditions, despite the patient's reluctance }\end{array}$} & Patients & 77 (51.3) & $13(8.7)$ & $60(40)$ \\
\hline & & Family companion & $105(70)$ & $12(8)$ & $33(22)$ \\
\hline \multirow{2}{*}{23} & \multirow{2}{*}{$\begin{array}{l}\text { It is the patients' right to specify to whom their } \\
\text { medical conditions should be delivered }\end{array}$} & Patients & $108(72)$ & $21(14)$ & $21(14)$ \\
\hline & & Family companion & $60(40)$ & $23(15.3)$ & $67(44.7)$ \\
\hline \multirow{2}{*}{24} & \multirow{2}{*}{$\begin{array}{l}\text { It is the right of the patient's family companion to } \\
\text { specify to whom the patient's medical conditions } \\
\text { should be delivered }\end{array}$} & Patients & $32(21.3)$ & $24(16)$ & $94(62.7)$ \\
\hline & & Family companion & $83(55.3)$ & $23(15.3)$ & $44(29.4)$ \\
\hline \multirow{2}{*}{25} & \multirow{2}{*}{$\begin{array}{l}\text { It is the medical staff who should state to whom } \\
\text { the patient's medical conditions should be deliv- } \\
\text { ered }\end{array}$} & Patients & $52(34.7)$ & $38(25.3)$ & $60(40)$ \\
\hline & & Family companion & $53(35.3)$ & $44(29.4)$ & $53(35.3)$ \\
\hline
\end{tabular}

patients. Moreover, $90 \%$ of the patients and their family companions believed that the patient's knowledge about his or her disease should be evaluated before breaking bad news. Then, the required information should be provided based on the patient's knowledge level.

Because of poor psychological state, malignancy of the disease, and the nature of bad news, some physicians may withhold medical information from the patients and open it up to their family to avoid patient disappointment 27 . In this study, $86.7 \%$ of the patients and $69.3 \%$ of the family companions believed that it is the patient's right to be informed about his or her medical condition.

Previous studies investigated the necessity of delivering bad news to cancer patients and its associated emotional impact and showed the lack of a distinctive difference between the informed and uninformed patients [27-32]. Breaking bad news to patients resolves their mental challenges that lie in the disease-pertinent uncertainties, provides them with an accurate viewpoint, and promotes their cooperation in the diagnosis process. Besides, greater trust is observed by the medical staff in relationship and cooperation with the patients.

Fifty-eight percent of the patients and $88.7 \%$ of their family companions believed that the physician should deliver bad news to the family companions before the patients. Studies suggested that in oriental family-centered societies, the family is accountable for making the decision instead of the patients [24, 25, 28, 30-32]. Comparison of Canadian and Spanish patients showed 
that the former group believed that the patients should be informed with complete and detailed information about their disease; whereas, $89 \%$ of Spanish families considered it unnecessary [21].

\section{Limitations and directions for future research}

Despite the same number of male and female patients admitted to the hospital (Equal full beds number), the lack of participation of more male patients in this study, studying in a limited time interval, and studying only one department of the hospital, could be considered some limitations of the study. On the other hand, considering that the study was carried out in the largest referral hospital in the northwest region of Iran, the patients and relatives of various academic levels and socioeconomic status from different parts of the northwest of the country participated in this study, so the results of the study can be generalized to the community but further supplementary studies may also be necessary to conduct in other areas and geographical locations, and in different hospitals and surgical departments (other than the internal), to obtain more accurate and comprehensible information. Also, in subsequent studies, considering the influence of inter-family relationships and the degree of dependence of relatives on communication and decision-making for the patient, as well as the role of different personality trait in this field, it seems necessary to determine the effect of these relationships on the performance of relatives and patients.

\section{Conclusion}

Patients tend to know about their disease and pertinent information and consider it among medical privacy, indicating a change in the way of thinking among Iranians. To preserve medical privacy, it is recommended to design a system that allows patients at the admission to the medical center to enlist their eligible family members to whom medical information can be delivered.

Disclosure of the patient's secret by claiming bad news to relatives is a major problem in protecting the privacy of patients, especially sick patients, therefore, in addition to teaching patients and relatives of the patients and medical personnel about the confidentiality of the medical and privacy of individuals, designing a system for identifying the person who is first informed about the patient condition that the patient declares during the first hospital admission will improve the quality of the patient's privacy.

Implementation of the Ministry of Health's training programs for patients, their relatives, and medical personnel can enhance the process of securing patients and reduce the unwanted and unethical expectations of relatives regarding the confidentiality of the patient's medical condition.

Implementing a system for identifying a person who is informed about the condition of the disease that the patient reports during the initial admission of the hospital can decrease the medical staff's confusion in preserving the medical secret, as well as the diagnosis of the recipient of bad news. Finally, this system will prevent the consequences of the disclosure of the patient's secret.

\section{Ethical Considerations}

\section{Compliance with ethical guidelines}

The project was approved by the Ethics Committee of Tabriz University of Medical Sciences under the codes: 5/4/7825(Oct/19/2015) and 5/4/8499(Nov/4/2015). All ethical principles were considered in this article. All procedures performed in this study involving human participants followed the ethical standards of the Institutional and or National Research Committee and were in compliance with the 1964 Helsinki Declaration and its later amendments or comparable ethical standards.

\section{Funding}

This research did not receive any specific grant from funding agencies in the public, commercial, or not-profit sectors.

\section{Author's contributions}

Conceptualization, study design: Maryam Zaare Nahandi, Ali Banagozar Mohammadi; Data analysis: Mohammad Asghari Jafarabadi, Kosar Ashrafrezaei, Marziyeh Shaker Saeedabad; Writing - original draft: Maryam Zaare Nahandi, Mehrnoosh Haghighatjou, Kosar Ashrafrezaei, Marziyeh Shakeri Saeedabad, Ahad Banagozar Mohammadi; Writing - review \& editing, investigation: All authors.

\section{Conflict of interest}

The authors declared no conflict of interest.

\section{Acknowledgements}

The authors would like to thank to the expert panel (Dr. Armin Sadeghi; Dr. Naser Moayednia; Dr. Ali Ostadi; Dr. Maryam Paeezi; Dr. Hamid Noshad; Dr. Mohammad Majidi; Dr. Rasoul Roshani; Dr. Soheil Teimouri; Dr. Ali Reza Ghaffari; Dr.Masoud Dinevari) for their contribution in the completion of the questionnaires and to determine the content validity and face validity of the 
questionnaires. We also would like to thank the Clinical Research Development Unit of Sina Educational, Research and Treatment Center, Tabriz University of Medical Sciences, Tabriz, Iran; for their assistance in this research.

\section{References:}

[1] Asemani O, Ebrahimi S. Medical confidentiality. Iran J Med Ethic Hist Med. 2014; 6(6):64-76. http://ijme.tums.ac.ir/article-1-5276-en.html

[2] Mahdavinejad G. Confidentiality in medical profession. Iran J Med Ethic Hist Med. 2008; 1(4):13-20. http://ijme.tums. ac.ir/article-1-295-en.html

[3] Parsa M, Bagheri A, Larijani B. Telling bad news and its various aspects. Iran J Med Ethic Hist Med. 2011; 4(6):1-14 http://ijme.tums.ac.ir/article-1-145-en.html

[4] Kazemi A, Pursoleimani A, Fakhari A, Madaen K. Truth telling in medicine: Views of Tabriz University of Medical Sciences. Iran J Med Ethic Hist Med. 2010; 3(2):54-63. http:// ijme.tums.ac.ir/article-1-5028-en.html

[5] Uprety D, Kasireddy V. Breaking bad news in cancer patients. SM J Commun Med. 2015; 1(1):1005. https://smjournals.com/community-medicine/fulltext/smcm-v1-1005.php

[6] Pereira CR, Calônego MA, Lemonica L, Barros GA. The P-A-CI-E-N-T-E Protocol: An instrument for breaking bad news adapted to the Brazilian medical reality. Rev Assoc Med Bras (1992). 2017; 63(1):43-9. [DOI:10.1590/1806-9282.63.01.43] [PMID]

[7] Narayanan V, Bista B, Koshy C. 'Breaks' protocol for breaking bad news. Indian J Palliat Care. 2010; 16(2):61-5. [DOI:10.4103/0973-1075.68401] [PMID] [PMCID]

[8] Baile WF, Buckman R, Lenzi R, Glober G, Beale EA, Kudelka AP. Spikes-A six-step protocol for delivering bad news: application to the patient with cancer. Oncologist. 2000; 5(4):302-11. [DOI:10.1634/theoncologist.5-4-302] [PMID]

[9] Kaplan M. SPIKES: A framework for breaking bad news to patients with cancer. Clinical journal of oncology nursing. 2010; 14(4):514-6. [DOI:10.1188/10.CJON.514-516] [PMID]

[10] Farokhyar N, Shirazi M, Bahador H, Baradaran HR, Jahanshir A. Assessing the validity and reliability of spikes questionnaires regard in of medical residents awareness breaking bad news in TUMS 2012. Razi J Med Sci. 2014; 21(122):29-36. http://rjms.iums.ac.ir/article-1-3285-en.html

[11] Garrett TM. Health care ethics: Principles and problems. New York City: Pearson; 2009. https://www.pearson.com/ us/higher-education/product/Garrett-Health-Care-EthicsPrinciples-and-Problems-5th-Edition/9780132187909.html

[12] Lo B. Resolving ethical dilemmas: A guide for clinicians. Philadelphia: Lippincott Williams \& Wilkins; 2012. https:// www.ovid.com/product-details.12535.html

[13] Mavroforou A, Giannoukas AD, Mavrophoros D, Michalodimitrakis E. Confidentiality governing surgical research practice. World J Surg. 2005; 29(2):122-3. [DOI:10.1007/ s00268-004-7678-8] [PMID]

[14] Bumb M, Keefe J, Miller L, Overcash J. Breaking bad news: An evidence-based review of communication models for oncology nurses. Clin J Oncol Nurs. 2017; 21(5):573-80. [DOI:10.1188/17.CJON.573-580] [PMID]

[15] Karimi Rozveh A, Nabi Amjad R, Karimi Rozveh J, Rasouli D. Attitudes toward telling the truth to cancer patients in Iran: A review article. Int J Hematol Oncol Stem Cell Res. 2017; 11(3):178-84. [PMID] [PMCID]

[16] de Pentheny O'Kelly C, Urch C, Brown EA. The impact of culture and religion on truth telling at the end of life. Nephrol Dial Transplant. 2011; 26(12):3838-42. [DOI:10.1093/ndt/ gfr630] [PMID]

[17] Surbone A, Ritossa C, Spagnolo AG. Evolution of truth-telling attitudes and practices in Italy. Crit Rev Oncol Hematol. 2004; 52(3):165-72. [DOI:10.1016/j.critrevonc.2004.09.002] [PMID]

[18] Gold M. Is honesty always the best policy? Ethical aspects of truth telling. Intern Med J. 2004; 34(9-10):578-80. [DOI:10.1111/j.1445-5994.2004.00673.x] [PMID]

[19] Hébert PC, Hoffmaster B, Glass KC, Singer PA. Bioethics for clinicians: 7. Truth telling. CMAJ. 1997; 156(2):225-8 [PMID] [PMCID]

[20] Fujimori M, Akechi T, Uchitomi Y. Factors associated with patient preferences for communication of bad news. Palliat Support Care. 2017; 15(3):328-35. [DOI:10.1017/ S147895151600078X] [PMID]

[21] Fainsinger RL, Núñez-Olarte JM, Demoissac DM. The cultural differences in perceived value of disclosure and cognition: Spain and Canada. J Palliat Care. 2003; 19(1):43-8. [DOI:1 0.1177/082585970301900108] [PMID]

[22] Hancock K, Clayton JM, Parker SM, Wal der S, Butow PN, Carrick S, et al. Truth-telling in discussing prognosis in advanced life-limiting illnesses: A systematic review. Palliat Med. 2007; 21(6):507-17. [DOI:10.1177/0269216307080823] [PMID]

[23] Sisk B, Frankel R, Kodish E, Harry Isaacson J. The truth about truth-telling in American medicine: A brief history. Perm J. 2016 20(3):15-219. [DOI:10.7812/TPP/15-219] [PMID] [PMCID]

[24] Zahedi F. The challenge of truth telling across cultures: A case study. J Med Ethics Hist Med. 2011; 4:11. [PMID] [PMCID]

[25] Bou Khalil R. Attitudes, beliefs and perceptions regarding truth disclosure of cancer-related information in the Middle East: A review. Palliat Support Care. 2013; 11(1):69-78. [DOI:10.1017/S1478951512000107] [PMID]

[26] Kazdaglis GA, Arnaoutoglou C, Karypidis D, Memekidou G, Spanos G, Papadopoulos O. Disclosing the truth to terminal cancer patients: A discussion of ethical and cultural issues. East Mediterr Health J. 2010; 16(4):442-7. [DOI:10.26719/2010.16.4.442] [PMID]

[27] Managheb SE, Hosseinpour M, Mehrabi F. Patient's viewpoints about how to break bad news. Iran J Microbiol. 2013; 6(4):68-79. http://ijme.tums.ac.ir/article-1-5184-en.html

[28] Sheu SJ, Huang SH, Tang FI, Huang SL. Ethical decision making on truth telling in terminal cancer: Medical students' choices between patient autonomy and family pater- 
nalism. Med Educ. 2006; 40(6):590-8. [DOI:10.1111/j.13652929.2006.02477.x] [PMID]

[29] Hagerty RG, Butow PN, Ellis PM, Lobb EA, Pendlebury SC, Leighl N, et al. Communicating with realism and hope: incurable cancer patients' views on the disclosure of prognosis. J Clin Oncol. 2005; 23(6):1278-88. [DOI:10.1200/ JCO.2005.11.138] [PMID]

[30] Yun YH, Kwon YC, Lee MK, Lee WJ, Jung KH, Do YR, et al. Experiences and attitudes of patients with terminal cancer and their family caregivers toward the disclosure of terminal illness. J Clin Oncol. 2010; 28(11):1950-7. [DOI:10.1200/ JCO.2009.22.9658] [PMID]

[31] Wang DC, Peng X, Guo CB, Su YJ. When clinicians telling the truth is de facto discouraged, what is the family's attitude towards disclosing to a relative their cancer diagnosis? Support Care Cancer. 2013; 21(4):1089-95. [DOI:10.1007/s00520012-1629-y] [PMID]

[32] Beqiri A, Toci E, Sallaku A, Qirjako G, Burazeri G. Breaking bad news in a Southeast European population: A survey among cancer patients in Albania. J Palliat Med. 2012; 15(10):1100-5. [DOI:10.1089/jpm.2012.0068] [PMID] 